guide will contribute to obesity or encourage consumption of fewer fruits and vegetables. Rather, it offers a greater degree of specificity and precision by demographic group, she argues.

None of the changes are written in stone, Bush adds, as Health Canada will complete consultations and conduct focus group testing before releasing the finished product - probably later this year. Both exercises were suspended until after the federal election, which may give influential groups such as the Dietitians of Canada time to weigh in - provided its members can reach a consensus, says director of policy Lynda Corby.

Others are convinced Health Canada is on the right track. "Overall, the direction seems appropriate," says Elinor Wilson, CEO of the Canadian Public Health Association.

"Given the obesity epidemic, pro- moting healthy eating is an important part of public policy," says Dr. Arya Sharma, chair of the Canadian Obesity Network. The guide is not a treatment for obesity, or diabetes or any other medical condition, he adds. "This is for someone who is healthy and wants a healthy diet."

Sharma believes the proposed guide is based on the best available science, but acknowledges that contradictory evidence is common in the nutrition sciences.

But Jeffery is so persuaded the revisions aren't evidence-based that he recommends Canadians look to the "Healthy Eating Pyramid" developed by Dr. Walter Willett at the Harvard School of Public Health as a superior, independent alternative for nutrition advice. - Wayne Kondro, Ottawa

DOI:I0.I503/cmaj.060039

\title{
Australian diet plan slammed
}

A ustralia's most popular diet plan - and the government science institute that backs it - is under fire for recommending excessive meat consumption and for its links with the meat and livestock industry.

The Commonwealth Scientific and Industrial Research Organisation (CSIRO), Australia's largest independent, scientific, industrial research body, touts the diet, published in book form as The CSIRO Total Wellbeing Diet, as beneficial for all. But according to an editorial in Nature (2005;438:1052) "the published research indicates that it is superior to a high carbohydrate diet only for a sub-population of overweight women with symptoms of metabolic dysfunction." It states that marketing of the book as "scientifically proven" was "decidedly unsavoury" and criticized Australia's national research agency for attaching its name to the book.

Leading Australian nutritionists Rosemary Stanton and Dr. John Tickell recently wrote an open letter to Prime Minister John Howard, expressing concern that the diet contains too much meat and asking him to review the book.

The CSIRO diet recommends 800 grams of red meat a week and up to 300 grams of meat daily; the Australian Government's Guide to Healthy Eating recommends 65 to Ioo grams of lean red meat 3 to 4 times a week.

The Meat and Livestock Industry Australia partly funded the research that supports the dietary recommendations.

Responding to the debate the Australian Health Minister Tony Abbott backed his government's guidelines on the National Health and Medical Research Council Web site.

The CSIRO Total Wellbeing Diet has sold more than 550 ooo copies in Australia (outselling Harry Potter and The Da Vinci Code), and roo ooo copies in the UK and New Zealand. It will soon be released in the US, Canada, India and South Africa. - Sally Murray, CMAJ

DOI:I0.I503/cmaj.o6oro4

\section{New Brunswick to get}

\section{medical school}

A new medical school in New Brunswick is raising hopes that the Maritime province will be able to more effectively recruit and retain physicians from within its own population.

The New Brunswick Medical Training Centre - the first of its kind in the province - will open its doors in Moncton in September.

Students and I8 new faculty members for the 4-year, French-language program are being recruited in a unique partnership between the University of Moncton and the University of Sherbrooke in Quebec. The University of Sherbrooke will provide the medical curriculum and grant the degree, but the teaching will be done at facilities in Moncton, allowing potential New Brunswick doctors to train in their home province.

Plans are also in the works for a satellite English program in Saint John, possibly by next year. Discussions are under way with the University of New Brunswick, and Memorial and Dalhousie universities.

"It's a very positive thing for New Brunswick," says Dr. Rose Anne Goodine, president of the New Brunswick Medical Society. "It's a lot harder for a young person to imagine being a doctor if there isn't a local program. I think that having a local program opens that door to more students."

According to the Canadian Institute for Health Information, New Brunswick and Prince Edward Island - the only provinces without medical schools had the lowest number of physicians per capita in Canada in 2004.

Goodine says New Brunswick's existing physician shortage will complicate faculty recruitment for the new programs. She hopes physicians continue to see patients but also "participate in more teaching."

The Moncton program will hire the new faculty over the next 3 years to handle clinical training, and hopes to graduate an average of 22 students a year, beginning in 2010. The Georges Dumont Hospital in Moncton will be the affiliated teaching hospital. 
Currently, NB medical students studying in French and enrolled in the Sherbrooke program split their 4-year degree between Sherbrooke and the University of Moncton and do their residencies at Dumont and other hospitals around the province.- Christine Morris, Fredericton

DOI:I0.1503/cmaj.060072

\section{Phase 2: Benchmarks to}

\section{accountability}

S etting wait times is not an end in itself, but a step toward a sustainable health care system, says the federal Wait Times Advisor.

Dr. Brian Postl said that instead of setting "hundreds and hundreds of benchmarks" we need to look at ways to make the first 5 benchmarks (CMAJ 2005;174:299), set in December, work. Postl addressed attendees at a Jan. I6 conference sponsored by the Canadian Health Coalition (CHC), a non-profit group that promotes medicare.

Sustainability depends on innovative operational improvements that will ensure appropriateness of care and consistent management, said Postl, president and CEO of the Winnipeg Regional Health Authority. Physician buy-in is also essential.

Postl's report on phase 2 of the federal wait times project, which will stipulate elements of system transformation, is due this spring.

In broad terms, Phase 2 will include engaging researchers to tie evidence to benchmarks, adopting new business practices, such as common wait lists for provinces or regions, employing wait-time coordinators so patients "know where they are," wait-time management training for health care professionals, and transparent waiting lists.

It will also outline the use of information technologies, including integration across health care systems and developing a registry.

Postl said physicians must also "take responsibility and change how they do business" by moving from a physician-based model to a program service-based culture. In the former, physicians "feel ownership of their patients" and refer them to, for example, a specific neurologist. Postl advocates a system where patients are assigned to a neurological service.

"We need to establish professional responsibility and accountability if this is going to work," said Postl. "We need physicians as part of it; we can't do it without them."

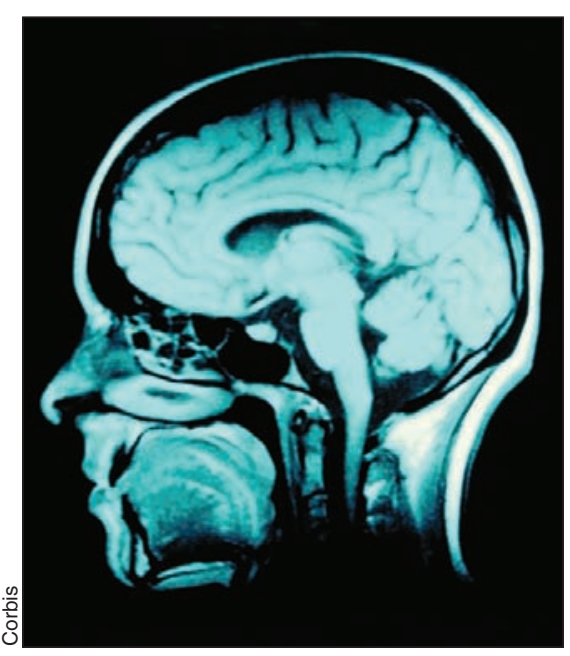

Using our head to reduce wait lists: about $5 \%$ of radiology imaging is unnecessary.

"One of the key issues around benchmarks and wait times, which we've done a very poor job of in this country, is the area of appropriateness," added Postl. There are some "remarkable inconsistencies across the country in how that's managed."

A case in point is the use of radiology services. A pilot study by the Canadian Association of Radiologists (CAR) found that $86 \%$ of radiology requests were appropriate, but in $9 \%$ of cases a more appropriate test should have been ordered and in $5 \%$ of cases no imaging was necessary for diagnosis or treatment.

This means that 4 million exams per year could be eliminated, saving about $\$ 500$ million or twice the annual equipment purchasing budget. This saving would mean the "elimination of wait times" and "the elimination of the need for private services," CAR's CEO Normand Laberge, told the conference. "We need to make sure we only do tests that will have a benefit."

Although these strategies are obviously needed, the problem is one of public perception, CHC Chair Kathleen Connors said at the conference. "The care guarantee has become the Trojan horse for for-profit health care." In an attempt to meet care guarantees, provinces will allow more privately delivered care, she maintained. - Barbara Sibbald, CMAJ

DOI:Io.I503/cmaj.o6oro6

\section{Quebec strain of C. difficile}

\section{in 7 provinces}

\section{$\mathrm{T}$} he same strain of Clostridium difficile that has caused close to I400 deaths in Quebec since 2003 is present in 7 provinces, the Public Health Agency of Canada is reporting.

The NAP I strain of $C$. difficile was found in hospitals in Ontario, Quebec, Nova Scotia, Newfoundland and Labrador, Alberta, Saskatchewan and British Columbia. The Canadian Nosocomial Surveillance Program participated in a 6-month study conducted by the Canadian Hospital Epidemiology Association and the Public Health Agency, and involving 34 hospitals that belong to the program (Fig. I).

From Nov. I, 2004, to Apr. 30, 2005, the National Microbiology Laboratory in Winnipeg collected more than 2000 stool samples and epidemiological data from patients at these institutions. The Public Health Agency has so far analyzed 615 of those samples and identified I847 cases of NAP I. Although they have not yet found the strain in New Brunswick and Manitoba, that may be because they still have more samples to investigate, says Denise Gravel, manager of the Nosocomial and Occupational Infections section of the Public Health Agency.

Compared to Agency data from a similar 1997 study, the incidence rate of $C$. difficile is essentially unchanged; $5.8 \%$ per 1000 hospital admissions in I997, and 6\% in the new study. But the 